\section{Transitions, Transition States, Transition State Analogues: Zinc Pyrazolylborate Chemistry Related to Zinc Enzymes}

\author{
HEINRICH VAHRENKAMP \\ Institut für Anorganische und Analytische Chemie, \\ Universität Freiburg, Albertstrasse 21, \\ D-79104 Freiburg, Germany
}

Received November 16, 1998

Zinc is known to be functional in almost 300 enzymes representing all subgroups of the enzyme classification. ${ }^{1}$ Although it is present in organisms only about half as much as its famous congener iron, it competes with the latter in terms of versatility. In comparison, the divalent metals magnesium and calcium, being 1-2 orders of magnitude more abundant, rarely share the biochemical abilities and rarely interfere with the biological functions of zinc, and the homologues of zinc, cadmium and mercury, just manage to exist as highly poisonous impurities. The question "Why?" suggests itself. What makes zinc, the "boring element without properties", so unique?

Like all "Why?", questions this one is difficult to answer. Definitely the redox inertness and the hard-soft properties of zinc play an important role. Unlike all other firstrow transition metals, zinc cannot get caught in a redox trap, i.e., change its properties by changing its oxidation state. Unlike calcium and magnesium, zinc likes to be coordinated by the soft donor functions in a protein environment, i.e., cysteine thiolate and histidine imidazole. Unlike cadmium and mercury, it does not hold on irreversibly to these donors. The intermediate nature of zinc in this respect, not really hard and not really soft, certainly makes it suitable to be bound to and to act in all available donor environments in living organisms.

The two aforementioned properties illustrate the availability of zinc for biological purposes. When it comes to usefulness, other properties must be named. The first of these is a combination of high (kinetic) lability and low (thermodynamic) stability, which characterizes the complexes of zinc more than those of any other transition metal. Unfortunately this combination, which is the

Heinrich Vahrenkamp received his Dr. degree in 1967 at the University of $\mathrm{M}$ unchen, working under the direction of $\mathrm{H}$. Noth in boron chemistry. After picking up cluster chemistry and X-ray crystallography from L. F. Dahl at the University of Wisconsin, he worked at the Universities of Marburg and Munchen on organometallic Lewis bases, becoming Privatdozent in 1972. In 1973 he was called to the chair of inorganic chemistry at the University of Freiburg where he has worked until today. After more than 20 years of research on polynuclear organometallic compounds, the main interest of his research group has now shifted to the coordination chemistry of zinc related to an understanding of its biological functions.

10.1021/ar9703185 CCC: $\$ 18.00$ Published on Web 04/06/1999 essence of catalysis, is an unpleasant symptom for a preparative chemist trying to build enzyme models.

In our opinion two other properties are the most important ones in zinc enzymes, specifically for the largest part of them effecting group transfer. They are the high nucleophilicity of "relevant" anions $\left(\mathrm{OH}, \mathrm{OR}, \mathrm{SR}, \mathrm{OPO}_{2} \mathrm{X}\right)$ when bound to tetrahedral zinc and the high coordinative flexibility in the ligand sphere of the metal. In an enzyme environment, the $\mathrm{Zn}-\mathrm{OH}$ function which exists at neutral $\mathrm{pH}$ is an equivalent of free $\mathrm{OH}^{-}$, and all zinc-catalyzed group-transfer reactions involve a rapid change of coordination numbers and coordination geometries at the zinc center. ${ }^{1}$

This Account is meant to provide some information from zinc coordination chemistry related to an understanding of these latter two phenemena. Both involve atomic interactions and atomic motions in the immediate environment of the metal ion, i.e., the inorganic part of zinc-catalyzed organic or biochemical reactions. We are well aware that the properties of "biological zinc" are a consequence of its "biological environment" and that the catalytic processes can only be understood by a full analysis of all environmental effects, i.e., the interactions of the substrate with the catalyst, solvent, enzyme interior, or cofactors. But the catalytic bond breaking and bond making take place when the reagents are bound to zinc. With this in mind we put up for discussion some observations from coordination chemistry and some generalizations drawn thereof.

On the basis of the fact that most zinc enzymes contain the catalytic zinc tetrahedrally coordinated by three protein side chains and the reagents (water, hydroxide, or substrate) as depicted below, we developed the "Freiburg enzyme model", which reliably reproduces this bonding situation. ${ }^{2}$ This enzyme model mimics the protein environment by attachment of the metal to three heterocyclic nitrogen donors of a tris(pyrazolyl)borate ligand and by encapsulation of the metal by the three substituents $R$ attached at the 3-positions of the pyrazole rings. Throughout this Account, the graphical symbol annotated as Tp*Zn will be used to represent the "enzyme" part of this model.

The Tp*Zn-X complexes have been found versatile in many respects. They allow a wide variation of substituents $X$. They are suitable for studying the properties of single $\mathrm{Zn}-\mathrm{X}$ units in a tetrahedral and hydrophobic environment, in this context the nucleophilicity of $X$. Due to their reasonably inert nature, they offer themselves for mechanistic studies, and the large amount of structural data gathered for them provides a basis for an evaluation of mechanistic pathways. Our contributions to pyrazolylborate-zinc chemistry started with invaluable help from the inventor of the ligands, Jerry Trofimenko. They grew complementary, in competition and in cooperation with the contributions by our colleagues G. Parkin, W. Kläui, W. Tolman, and the late N. Kitajima.

VOL. 32, NO. 7, 1999 / ACCOUNTS OF CHEMICAL RESEARCH 

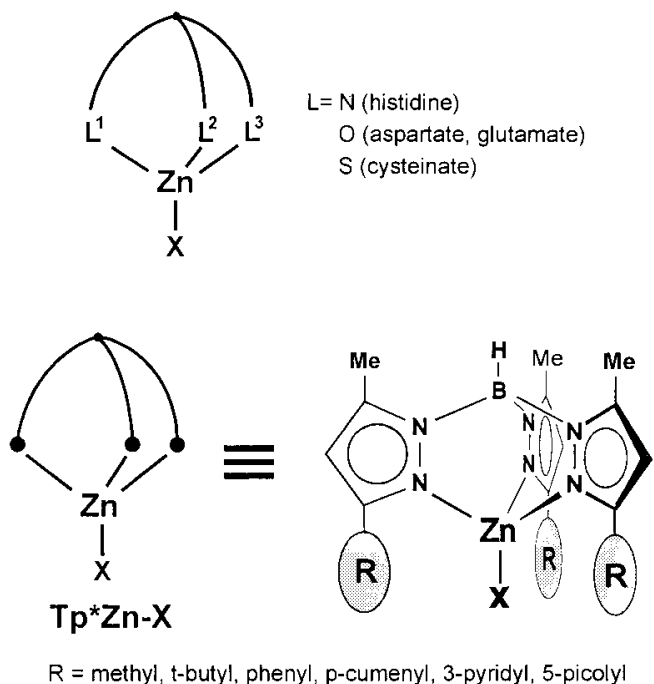

\section{The Tp*Zn-X Nucleophile}

It is generally accepted that hydrolytic zinc enzymes attack their substrates (peptides, esters, $\mathrm{CO}_{2}$, phosphates, etc.) by an enzyme-bound $\mathrm{Zn}-\mathrm{OH}$ unit, resulting from the resting enzyme's $\mathrm{Zn}-\mathrm{OH}_{2}$ unit. ${ }^{1}$ Mechanistic details of this attack will be discussed below. This $\mathrm{Zn}-\mathrm{OH}$ unit, i.e., a molecular metal hydroxide, must be a powerful nucleophile, considering the efficiency of the enzyme catalysts. It is formed in the environment of the living cell, that is, near neutral $\mathrm{pH}$. Thus, the zinc ion in its protein surroundings decreases the $\mathrm{pK}_{\mathrm{a}}$ of water by about 7 units. The enzyme-bound $\mathrm{Zn}-\mathrm{OH}$ unit has the combined advantage of making hydroxide available around $\mathrm{pH} 7$, of facilitating its approach to the substrates due to the fact that it does not bear a negative charge, and of enhancing the catalytic activity by the presence of zinc as an electrophilic center.

While it is a triviality that all hydrated metal salts are Brønsted acids and that this is specifically the case for zinc halides, the depression of the $\mathrm{pK}_{\mathrm{a}}$ of water to a value of 7 by a divalent metal ion is still unique. One should recall that the hexahydrate of $\mathrm{Al}^{3+}$ has a $\mathrm{pK}_{\mathrm{a}}$ of 5.0 and the hydrated $\mathrm{Zn}^{2+}$ ion is just as acidic as the ammonium ion, having a $\mathrm{pK}_{\mathrm{a}}$ of 9.5. Thus, the ligand environment of zinc must provide another 2-3 $\mathrm{pK}_{\mathrm{a}}$ units. Accordingly, a number of $\mathrm{L}_{n} \mathrm{Zn}-\mathrm{OH}_{2}$ complexes were found which have $\mathrm{pK}_{\mathrm{a}}$ values of 7-8, and $\mathrm{MO}$ calculations were performed in trying to evaluate the underlying effects. ${ }^{3}$ However, prior to our own work no mononuclear $\mathrm{L}_{n} \mathrm{Zn}-\mathrm{OH}$ complex was isolated as such and structurally characterized. We did this in the solid state for the Tp*Zn-OH complexes with 3-tert-butyl4a and 3-p-cumenyl substituents, ${ }^{4 b}$ and in solution for those with phenyl ${ }^{4 c}$ and pyridyl substituents ${ }^{2 \mathrm{~d}}$ on the Tp* ligands. These $\mathrm{Tp} * \mathrm{Zn}-\mathrm{OH}$ complexes which can be easily prepared and stored without precaution ${ }^{2}$ represent the resting state of the Freiburg enzyme model.

The determination of their $\mathrm{pK}_{\mathrm{a}}$ values has provided the justification for calling them enzyme models. Figure 1 demonstrates this by a comparison of $\mathrm{Zn}-\mathrm{OH}_{2} \mathrm{com}$ plexes $^{5}$ for which coordination numbers 6,5 , and 4 were
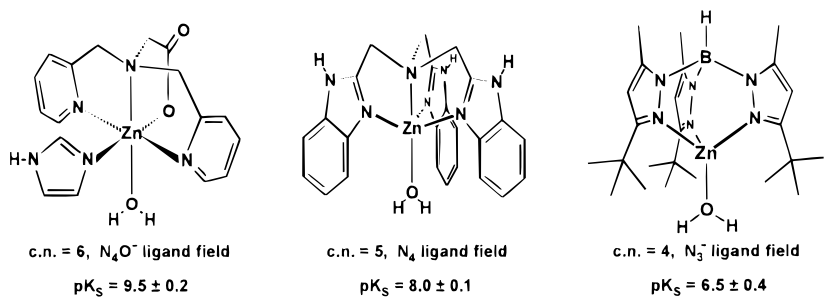

FIGURE 1. Comparison of acidities of $\mathrm{Ln}_{n} \mathrm{Zn}-\mathrm{OH}_{2}$ complexes with tripodal ligands, having coordination numbers 6,5 , and 4 .

ascertained by structure determinations. In all three cases a tripodal nitrogen ligand is present, being tetradentate in the first two cases and being accompanied by a monodentate nitrogen donor in the first case. In this structurally homologous series the effect of coordination number on $\mathrm{pK}_{\mathrm{a}}$ is striking, yielding a linear progression from left to right. The $\mathrm{pK}_{\mathrm{a}}$ of the $\left[\mathrm{Tp} * \mathrm{Zn}-\mathrm{OH}_{2}\right]^{+}$complex is the lowest of any $\mathrm{Zn}-\mathrm{OH}_{2}$ complex that we are aware of, and according to its value below 7 the compound is not isolated as the zinc-aqua cation but as the neutral species $\mathrm{Tp} * \mathrm{Zn}-\mathrm{OH} .{ }^{4 a}$

Serendipitously we ran into another demonstration of the fact that the $\left[\mathrm{Tp} * \mathrm{Zn}-\mathrm{OH}_{2}\right]^{+}$species have $\mathrm{pK}_{\mathrm{a}}$ values near 7. By using the wrong amount of $\mathrm{KOH}$ in the preparation of the $\mathrm{Tp} * \mathrm{Zn}-\mathrm{OH}$ complex, its partially protonated equivalent la was obtained. Carefully keeping the $\mathrm{pH}$ near 7 then produced all three $\mathrm{H}_{3} \mathrm{O}_{2}$-bridged dinuclear complexes $1^{2 \mathrm{c}}$ These complexes with their bridging

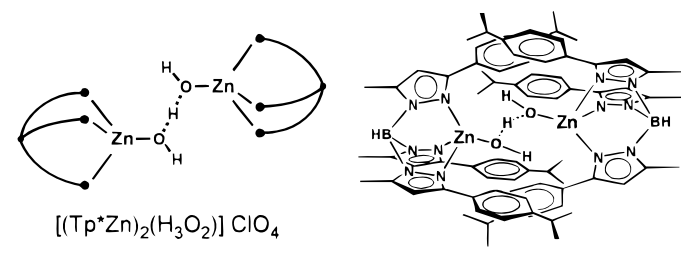

1a: $R=$ p-cumenyl, 1b: $R=3$-pyridyl, $1 \mathrm{c}: R=5$-picolyl

hydrated hydroxide ligands are structural representations of the equilibrium law: for $\mathrm{pK}=\mathrm{pH}$ an acid is $50 \%$ deprotonated. The drawing of the structure of $\mathbf{l a}$ on the right side demonstrates how the acid-base functions of this compound are completely encapsulated in the hydrophobic environment of the organic substituents of the pyrazolylborates. This hydrophobic interior certainly is an important factor allowing for the low $\mathrm{pK}_{\mathrm{a}}$ values and the nucleophilic strength of the $\mathrm{Tp} * \mathrm{Zn}-\mathrm{OH}$ complexes.

The term "enzyme model" requires enzyme-like reactions. We have found such reactions for practically all classes of hydrolytic zinc enzymes. ${ }^{6}$ The $\mathrm{Tp} * \mathrm{Zn}-\mathrm{OH}$ complexes induce nucleophilic cleavage of substrates according to eq 1 . The molecular species $\mathrm{Tp} * \mathrm{Zn}-\mathrm{OH}$ and $\mathrm{Tp} * \mathrm{Zn}-\mathrm{O}-\mathrm{E}$ are immiscible with water, and hence water cannot be introduced as a reagent. For this reason the reactions are stoichiometric rather than catalytic and there is no turnover involving the regeneration of $\mathrm{Tp} * \mathrm{Zn}-\mathrm{OH}$ from $T p * Z n-O-E$. This must await the availability of water-soluble Tp* ligands. Irrespective of this the ease of the cleavage reactions demonstrates what was to be demonstrated: the nucleophilicity of the $\mathrm{Zn}-\mathrm{OH}$ unit. 


\begin{tabular}{llll}
$\mathrm{Tp}^{*} \mathrm{Zn}-\mathrm{OH}+\mathrm{E}-\mathrm{X}$ & $\rightarrow \mathrm{Tp} \mathrm{Zn}^{*}-\mathrm{O}-\mathrm{E}+\mathrm{HX} \quad$ (1) \\
$\mathrm{E}$ & $\mathrm{X}$ & substrate & ref. \\
\hline $\mathrm{RC}(0)$ & $\mathrm{OR}$ & ester & $6 \mathrm{a}$ \\
$\mathrm{RC}(0)$ & $\mathrm{NH}_{2}$ & amide & $6 \mathrm{a}$ \\
$\mathrm{ROC}(0)$ & $\mathrm{OC}(0) \mathrm{OR}$ & pyrocarbonate & $2 \mathrm{a}$ \\
$(\mathrm{RO})_{2} \mathrm{P}(0)$ & $\mathrm{OR}$ & organophosphate & $6 \mathrm{~b}$ \\
$(\mathrm{RO})_{2} \mathrm{P}(0)$ & $\mathrm{OP}(0)(\mathrm{OR})_{2}$ & pyrophosphate & $6 \mathrm{c}$ \\
$\mathrm{RSO}{ }_{2}$ & $\mathrm{OP}(0)(\mathrm{OR})_{2}$ & sulfonatophosphate & $6 \mathrm{c}$ \\
sugar phosphate & $\mathrm{OR}$ & nucleotide derivative & $6 \mathrm{~d}$
\end{tabular}

Another type of hydrolytic reaction, exemplified by the biological function of carbonic anhydrase, is incorporation rather than cleavage of a small molecule substrate. We could model this function by $\mathrm{CO}_{2}$ incorporation according to eq 2, the evidence for the bicarbonate complex resting in spectroscopic data. ${ }^{2 a}$

$$
\mathrm{Tp} * \mathrm{Zn}-\mathrm{OH}+\mathrm{CO}_{2} \rightarrow \mathrm{Tp} * \mathrm{Zn}-\mathrm{OC}(\mathrm{O}) \mathrm{OH}
$$

By varying the conditions of the $\mathrm{CO}_{2}$ reactions, derivatives of the bicarbonate complexes were obtained. They are listed below together with the products of other incorporations of small molecules. ${ }^{2 a, 4 b}$ All these reactions are fast and quantitative and lead to crystalline materials. Basically they are all acid-base reactions which can be described mechanistically as additions of $\mathrm{Zn}-\mathrm{OH}$ across a double bond followed by a condensation reaction.

\begin{tabular}{ll} 
substrate & product \\
\hline $\mathrm{CO}_{2}$ & $\left(\mathrm{Tp}^{*} \mathrm{Zn}-\mathrm{O}\right)_{2} \mathrm{CO}$ \\
$\mathrm{CO}_{2}$ /alcohol & $\mathrm{Tp}^{*} \mathrm{Zn}-\mathrm{O}-\mathrm{C}(\mathrm{O}) \mathrm{OR}$ \\
$\mathrm{SO}_{2}$ & $\left(\mathrm{Tp} \mathrm{Z}^{*} \mathrm{Zn}-\mathrm{O}\right)_{2} \mathrm{SO}$ \\
$\mathrm{RNCS}$ & $\mathrm{Tp} \mathrm{P}^{*} \mathrm{Zn}-\mathrm{O}-\mathrm{C}(\mathrm{S}) \mathrm{NHR}$
\end{tabular}

In principle any ligand with an unshared electron pair bound in a monodentate fashion to low-coordinate zinc should be a good Lewis base and possibly a strong nucleophile. On the textbook level this is borne out by the fact that all zinc alkoxides derived from simple aliphatic alcohols are oligomeric, and that thiolate ligands in zinc complexes are bridging unless their terminal nature is supported by, e.g., chelate effects, the highly favored $\mathrm{ZnN}_{2} \mathrm{~S}_{2}$ coordination, or a negative charge of the complexes. Our experience has shown that all these problems are eliminated by the use of Tp* ligands. Except for being easily hydrolyzed to $\mathrm{Tp} * \mathrm{Zn}-\mathrm{OH}$, the terminal alkoxide ligands stay monodentate, and terminal thiolates including SH make perfectly stable complexes of the types $\mathbf{2}$ and 3. ${ }^{4 b, c, 7,8}$

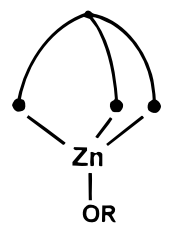

2

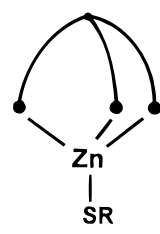

3
It looks like there is biological relevance in these two complex types which has yet to be exploited. The $L_{3} Z n-$ OR situation represents the activated alcohol in horse liver alcohol dehydrogenase, an enzyme whose model chemistry is badly underdeveloped. The $L_{3} Z n-S R$ situation is just becoming prominent after the discovery of several zinc enzymes that catalyze alkyl group transfer to thiolates, the most prominent of which being cobalamine independent methionine synthase, methanol:CoM methyltransferase, and the DNA repair enzyme Ada. ${ }^{9}$ There is evidence that in all three cases the thiolate substrate is bound to zinc when it is methylated. The alkylation reaction can then be formulated as a nucleophilic substitution at the alkylating reagent according to eq 3 . A significant part of

$$
\mathrm{L}_{3} \mathrm{Zn}-\mathrm{SR}+\mathrm{Me}-\mathrm{X} \rightarrow \mathrm{L}_{3} \mathrm{Zn}-\mathrm{S}(\mathrm{Me}) \mathrm{R}+\mathrm{X}
$$

the driving force of this reaction comes from the poor donor qualities of thioethers toward zinc, which causes liberation of the product (presumably through replacement by water) and the start of a new catalytic cycle.

Our Tp*Zn-SR complexes model this reaction in a simple and straightforward way under physiological conditions, i.e., at neutral $\mathrm{pH}$ : the "resting enzyme" (Tp*Zn$\mathrm{OH}$ ) forms from $\mathrm{Tp}^{*-}, \mathrm{Zn}^{2+}$ and water at neutral $\mathrm{pH}^{2}$ its $\mathrm{OH}^{-}$ligand is replaced by $\mathrm{SR}^{-}$upon treatment with thiols without $\mathrm{pH}$ effects, ${ }^{4 b, 8}$ and alkylation of Tp*Zn-SR is facile using methyl iodide or trimethylsulfonium salts. ${ }^{10}$ The resulting thioethers are immediately released, being replaced in these reactions by halide anions, see eq 4.

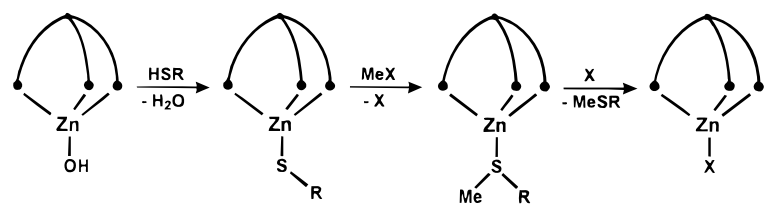

The unwillingness of zinc to bind to thioethers is unique. It sheds light on the second "catalytic" property of the monodentate ligands $\mathrm{OH}, \mathrm{OR}$ or SR in Tp*Zn-X: in addition to being strong nucleophiles they are also good leaving groups.

\section{Frozen Enzymes}

Having addressed the nucleophilicity and lability of the zinc-bound catalytic agents in $\mathrm{L}_{3} \mathrm{Zn}-\mathrm{X}$ species, attention has to be shifted back to the zinc ion itself. The classical understanding of metal ion catalyzed reactions assigns the role of the electrophile to it which is responsible for activating the substrates for nucleophilic attack. With the nucleophile being a ligand of the zinc ion, this comes down to 2-fold interaction between the catalyst and substrate involving four-center reaction intermediates. Terms such as concerted, or mixed, or hybrid mechanism have been used to describe this situation, and there is good evidence for it from enzymatic, simple mechanistic, and theoretical investigations. ${ }^{11}$

On the side of the zinc ion this implies a change of the coordination number from 4 to 5 and back to 4 in the 
catalytic process. Specifically for hydrolytic enzymes, intermediates such as A (for esters and peptides) or B (for

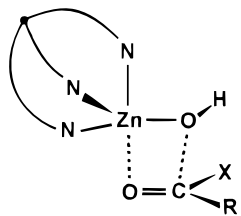

A

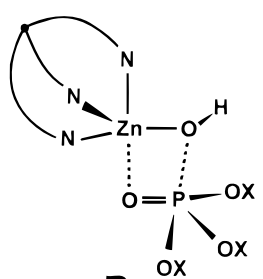

B
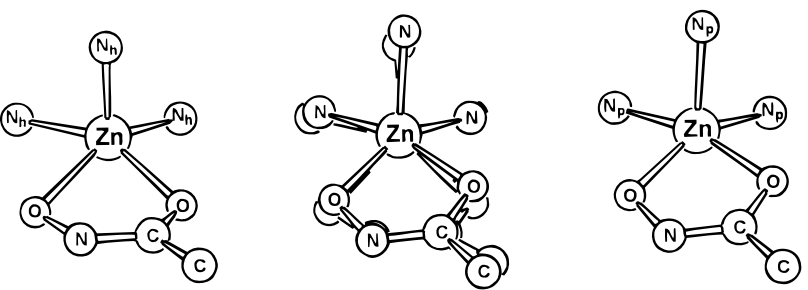

FIGURE 2. Superposition of the zinc-ligand environments of the hydroxamate complexes of neutrophil collagenase (left, $\mathrm{N}_{\mathrm{h}}=$ histidine nitrogens) and Tp*Zn (right, $\mathrm{N}_{\mathrm{p}}=$ pyrazole nitrogens).

phosphate esters or oligophosphates) must be invoked as activated complexes or transition states. The coordinative flexibility of zinc allows for the rapid change of the coordination number, and the enzymatic pockets around the metal ion must allow the motion of the substrate and the transport of the reagents associated with it.

If now a substrate is bound to zinc in a fashion comparable to $\mathbf{A}$ or $\mathbf{B}$ but does not undergo any further reaction, we have a case of efficient enzyme inhibition. Inhibitor substrates of this class have been named transition state analogues..$^{13} \mathrm{In}$ the field of hydrolytically active zinc enzymes the hydroxamates have become popular as such inhibitors, since they were found to be potent blockers and transition state models of metalloproteases as well as of the $(0,0)$ chelating situation occurring during glycoside transformations. ${ }^{14}$ As a typical example $\mathbf{C}$ and D represent the zinc-bound enediolate transition state
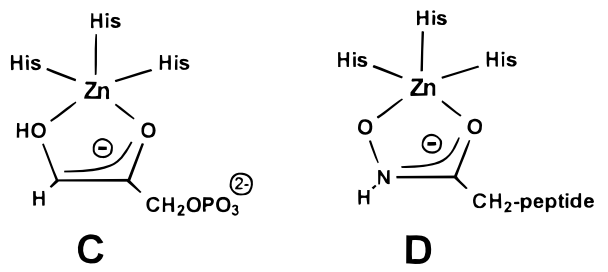

proposed for interconversions of the sugar fragment dihydroxyacetone phosphate ${ }^{14 b}$ and its transition state analogue in hydroxamate-inhibited class II aldolases. ${ }^{15}$ The quality and versatility of hydroxamate inhibitors for matrix metalloproteases have spurred intense pharmaceutical research as they may be useful as drugs against degenerative diseases such as arthritis. ${ }^{16}$ In line with this quite a series of hydroxamate-inhibited zinc enzymes has been subjected to crystal structure analyses. ${ }^{15,17}$

Using pyrazolylborate zinc complexes, it was easy to reproduce both the enzyme-substrate complex $\mathbf{C}$ and the enzyme-inhibitor complex D with simple bidentate ligands. ${ }^{18}$ The minimal structural representations hydroxyacetone and acetohydroxamic acid yielded the model complexes $\mathbf{4}$ and $\mathbf{5}$. A similar coordination pattern is
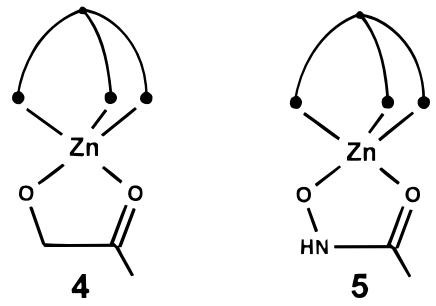

realized with the bidentate $\beta$-diketonate ligands. Other hydroxamates including the established enzyme inhibitor ZINCOV, a hydroxamate derivative of the tripeptide LeuAlaGly, bind to Tp*Zn in the same way.

The relation between complex $\mathbf{5}$ and the corresponding enzyme-inhibitor complex, i.e., the "frozen enzyme", is more than a formality. Figure 2 demonstrates this by graphical superposition. The zinc environments of neutrophil collagenase complexed with 2-hydroxamatomethyl-4-methylpentanoyl-phenylalanyl-methylamide ${ }^{17 a}$ (left) and of the complex Tp*Zn(acetohydroxamate) (5, right) correspond so closely that in the superposition (center) none of the individual component atoms is more than $0.2 \AA$ away from its equivalent. Thus, in the model complexes just like in the reacting enzymes the hydroxamate ligands act like pseudosubstrates which prefer a bonding situation normally existing only transiently to such an extent that they "freeze" the system with coordination number 5 .

The small molecule models of the transition state analogues cannot lead the way to drug design as the between their organic groups and the surrounding enzyme. They do, however, justify their formulation as transition state analogues by their structural flexibility: while the acetohydroxamate complex of $\mathrm{Tp} * \mathrm{Zn}$ is close to square pyramidal (TBP' index 0.3 , see below), the ZINCOV complex of the same Tp*Zn unit is close to trigonal bipyramidal ${ }^{18}$ (TBP' index 0.9). Thereby they are reminders of the geometrical softness of transition states in general and those of coordination number 5 in particular. By showing this flexibility, they directed our attention to the question of how atoms move around the catalytic center during the passage from substrate to product in the ligand sphere of five-coordinate zinc.

\section{Motion around Zinc}

There exists a large body of information on the kinetics and proposed mechanisms of hydrolytic substrate cleavages brought about by zinc enzymes or model complexes with polydentate ligands. ${ }^{11}$ The essentials have already been mentioned: the active nucleophile is the $\mathrm{Zn}-\mathrm{OH}$ unit, and the zinc ion is involved as the electrophile in the hybrid mechanism depicted in $\mathbf{A}$ or $\mathbf{B}$. It seems to us that the intimate prodeedings of the catalytic event, i.e., the bond breaking and bond making in the substrate, take place in the ligand sphere of only onezinc ion. This should specificity of the inhibitors rests in the interactions 
not be in contradiction with the fact that several zinc enzymes contain two closely spaced zinc ions in the catalytic center, as it has been found that the zinc ions in bimetallic enzymes normally are unsymmetrically coordinated, allowing only one of them to become the $\mathrm{M}-\mathrm{OH}$ unit which is hydrolytically active. ${ }^{19}$ With this in mind and on the basis of the mechanistic information gathered by others $^{11}$ and ourselves ${ }^{12}$ on the hydrolytic activity of mononuclear zinc complexes, we have proposed a trajectory for hydrolytic reactions brought about by $\mathrm{L}_{3} \mathrm{Zn}-\mathrm{OH}$ species. ${ }^{12}$ The sequence under consideration is shown as eq 5 containing the four-center intermediate and a car-

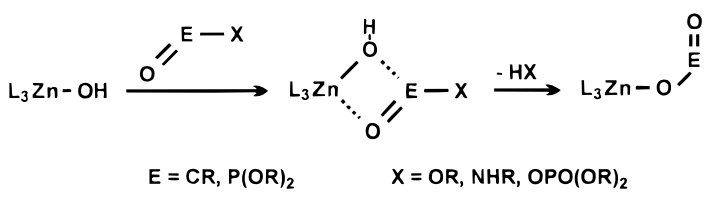

boxylate or phosphate complex as the reaction product $\mathrm{L}_{3} \mathrm{Zn}-\mathrm{O}-\mathrm{E}=\mathrm{O}$. It describes a stoichiometric hydrolysis consuming one $\mathrm{L}_{3} \mathrm{Zn}-\mathrm{OH}$ and one $\mathrm{O}=\mathrm{E}-\mathrm{X}$. In a catalytic process $\mathrm{L}_{3} \mathrm{Zn}-\mathrm{OH}$ is regenerated from $\mathrm{L}_{3} \mathrm{Zn}-\mathrm{O}-\mathrm{E}=\mathrm{O}$ by replacement with water and deprotonation.

Focusing the attention on the events in the ligand sphere of zinc, it can be seen that the evolution of the coordination pattern is $\mathrm{L}_{3} \mathrm{ZnO}^{1} \rightarrow \mathrm{L}_{3} \mathrm{Zn}\left(\mathrm{O}^{1}, \mathrm{O}^{2}\right) \rightarrow \mathrm{L}_{3} \mathrm{ZnO}^{2}$. In the activated complex $\mathrm{O}^{1}$ and $\mathrm{O}^{2}$ occupy cis-positions, and in passing through the transition state the $\mathrm{Zn}-\mathrm{O}^{1}$ bond is given up concomitantly with the formation of the $\mathrm{Zn}-\mathrm{O}^{2}$ bond. It is to be assumed that the entering substrate (represented by $\mathrm{O}^{2}$ ) approaches the zinc ion through one $\mathrm{L}_{2} \mathrm{O}^{1}$ face of the $\mathrm{L}_{3} \mathrm{ZnO}^{1}$ tetrahedron. Similarly the completion of the hydrolysis consists of the removal of the nucleophile (represented by $\mathrm{O}^{1}$ ) outward from one $\mathrm{L}_{2} \mathrm{O}^{2}$ face of the resulting $\mathrm{L}_{3} \mathrm{ZnO}^{2}$ tetrahedron. Each of these movements is represented geometrically by a passage along the axis of a distorted trigonal bipyramid. Figure 3 displays this interconversion for a zinc ion attached to three nitrogen donors of an enzyme or a tridentate ligand. One should note that two different $\mathrm{N}_{2} \mathrm{O}$ faces, i.e., two different trigonal bipyramids, are involved as represented by $\mathbf{E}$ and $\mathbf{G}$.

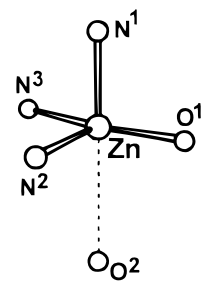

E

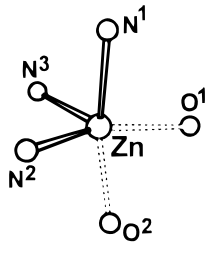

F

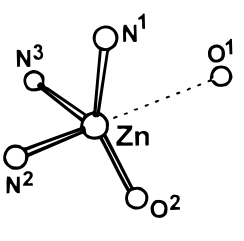

G
FIGURE 3. Evolution of the coordination environment of zinc during substrate hydrolysis.

It suggests itself that the ligand motions occurring here for five-coordinate zinc are those of a Berry pseudorotation, the lowest energy fluxional process interconverting two different trigonal bipyramids. Berry pseudorotation has a square-pyramidal transition state, corresponding here to the situation $\mathbf{F}$ with the $\mathrm{Zn}-\mathrm{O}^{1}$ bond half broken and the $\mathrm{Zn}-\mathrm{O}^{2}$ bond half formed. It was the agreement between this hypothetical transition state geometry and that of the transition state analogue complex $\mathbf{5}$ that made us believe in the justification of the term "transition state analogues" and made us aware of the ability to deduce mechanism from structure as discussed below.

The method of choice was the structure correlation method developed by Bürgi and Dunitz. ${ }^{20}$ We noticed that it should be applicable to pyrazolylborate zinc complexes when we observed the distinct structural differences between the Tp*Zn-acetohydroxamate complex $\mathbf{5}$ and its ZINCOV analogue; see above. We then found that, although pyrazolylborates with bulky substituents were initially assumed to be tetrahedral enforcers, there are more than 50 structures of five-coordinate Tp*Zn complexes documented, 30 of which can be grouped as Tp*Zn$(X)(Y)$ with truly five-coordinate zinc. ${ }^{11}$ We have contributed to this group some Tp*Zn complexes in which both a "substrate" and a "reagent", i.e., phosphate and water, are coordinated to the same zinc ion. ${ }^{6}$ The $30 \mathrm{Tp} * \mathrm{Zn}(\mathrm{X})$ (Y) complexes were found to be suitable for the structure correlation analysis and the development of a Berry pseudorotation-like pathway between two different trigonal-bipyramidal geometries.

Of the various procedures for assessing the deviations of five-coordinate species from the ideal trigonal-bipyramidal (TBP) or square-pyramidal (SP) geometries, the simplest one considers only the two largest bond angles. ${ }^{21}$ These angles ( $1-5$ and $2-4$ in Figure 4$)$ are $180^{\circ} / 120^{\circ}$ for TBP and $150^{\circ} / 150^{\circ}$ for SP. Their difference or a function derived thereof can be considered as an index for the "amount TBP" of the complex, being unity for pure TBP and zero for pure SP. A plot of the angles or their difference against a suitable coordinate can be used to visualize whether a given complex geometry lies on the Berry line, the lowest energy pathway from TBP to SP. Figure 4 does this for the $30 \mathrm{Tp} * \mathrm{Zn}(\mathrm{X})(\mathrm{Y})$ complexes by the established procedure. ${ }^{21}$

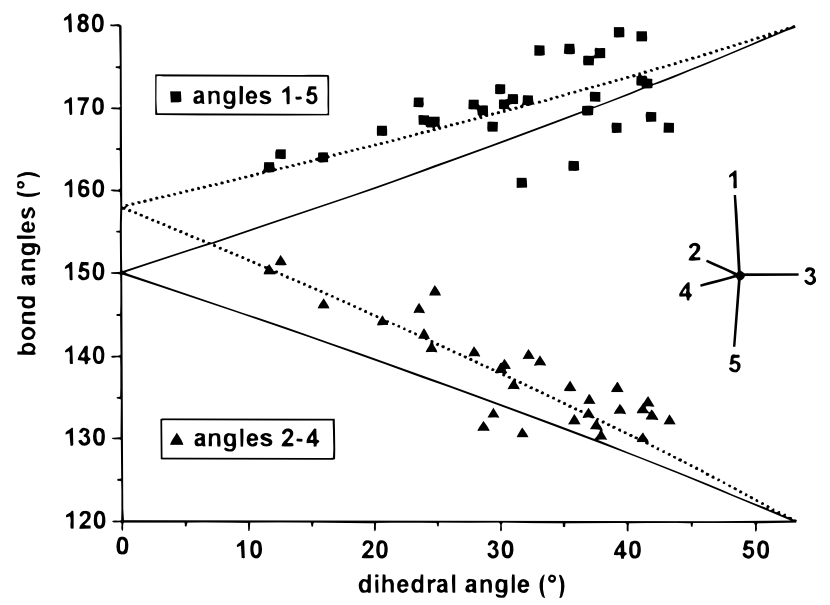

FIGURE 4. Bond angles ( $1-5$ and $2-4$ ) against the dihedral angle $\delta_{24}$ (the angle between the normals to the two trianguar faces $1-2-4$ and $5-2-4)$ for $\operatorname{Tp} * Z n(X)(Y)$ complexes. $\delta_{24}$ is $0^{\circ}$ for the ideal $S P$, and $53.1^{\circ}$ for the ideal TBP.

In Figure 4 the two curves describing the ideal Berry transition are given as solid lines. It is obvious that the 
$\mathrm{Tp} * \mathrm{Zn}(\mathrm{X})(\mathrm{Y})$ complex geometries do not follow this ideal transition but a modified one which is represented by the dotted lines. This, however, conforms to the observation 20a that in five-coordinate metal complexes basal angles of $158^{\circ}$ rather than $150^{\circ}$ represent the "best" squarepyramidal geometry and to the notion that the limited flexibility of an enzymatic environment as well as of the Tp* ligands renders the full $120^{\circ} \rightarrow 150^{\circ}$ and $180^{\circ} \rightarrow 150^{\circ}$ transitions unaccessible. A quantitative treatment of this ${ }^{12}$ yields an analytical representation of the dotted curves in Figure 4. This modified Berry pseudorotation, displayed by the structures of the $30 \mathrm{Tp} * \mathrm{Zn}(\mathrm{X})(\mathrm{Y})$ complexes, just like the ideal one describes a TBP $\rightarrow$ SP transition under $\mathrm{C}_{\mathrm{m}}$ symmetry.

A more general way of describing $\mathrm{ML}_{5}$ structures on the Berry line, i.e., the ideal TBP $\rightarrow$ SP transition, is that of the dihedral angle sums. ${ }^{21}$ For the modified Berry transition it leads to a maximal sum of absolute dihedral angle differences $\Sigma(\Delta \delta)$ of $202.3^{\circ}$ corresponding to the "distance" between the ideal TBP and the ideal SP. 12 In a diagram with $\Delta \delta$ values on both coordinates a straight line connecting both $202.3^{\circ}$ points describes the $\sum(\Delta \delta)$ values for geometries lying on the Berry transition from TBP to SP. Figure 5 is such a plot for the $30 \mathrm{Tp} * \mathrm{Zn}(\mathrm{X})(\mathrm{Y})$ complexes. The adherance of almost all points to the adapted Berry line is striking. It confirms that under the constraints of the Tp* ligand geometry the structures of the $\operatorname{Tp} * \mathrm{Zn}(\mathrm{X})(\mathrm{Y})$ complexes describe a Berry pseudorotation-like motion of a $\mathrm{ML}_{5}$ system. By taking the $\Sigma(\Delta \delta)$ values for the individual complexes and scaling them against the value of $202.3^{\circ}$, their "amount TBP" or "amount SP" can be measured as a number between 0 and 1 . This way the above-mentioned TBP indices for $\mathbf{5}$ and its ZINCOV analogue were determined.

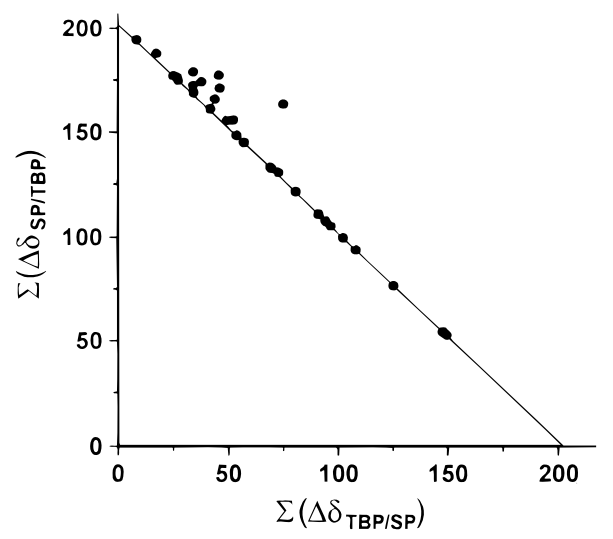

FIGURE 5. $\sum(\Delta \delta)$ values for the $T p * Z n(X)(Y)$ complexes. For detailed explanations see refs 12 and 21 .

Having demonstrated that the structures of the Tp*Zn$(X)(Y)$ complexes define a sequence of points on an adapted Berry transition, a visualization of this transition could be expected to confirm the conclusions to be drawn thereof. Figure 6 is meant to demonstrate this. In Figures 6 and 7 the pyrazolylborate-zinc unit is reduced to the $\mathrm{BN}_{6} \mathrm{Zn}$ bicyclooctane skeleton, atoms N1, N2, and N3 correspond to positions 1, 2, and 3 in the inset of Figure 4, and atoms $X$ and $Y$ correspond to positions 4 and 5 .
The molecules in Figure 6 are oriented such that a perfect $\mathrm{TBP}^{\prime} \rightarrow \mathrm{SP}^{\prime}$ transition requires that $\mathrm{N} 1$ and $\mathrm{Y}$ move in the plane of the drawing while $\mathrm{N} 2$ and $\mathrm{X}$ move in a plane almost perpendicular to it, as they do to a good approximation. During the simultaneous motion of $X$ and $Y$ the $Z n-Y$ bond decreases in length from right to left while the $Z n-X$ bond increases in length from back to front, as it has to be for the simultaneous bond making $(Z n-Y)$ and breaking $(\mathrm{Zn}-\mathrm{X})$. In the 30 complexes $T p * Z n(X)(Y)$, $\mathrm{Zn}-\mathrm{X}$ actually varies between 1.85 and $2.03 \AA$ and $\mathrm{Zn}-\mathrm{Y}$ between 3.02 and $2.04 \AA$. Thus, the actual "motion" of the structures in space verifies the results of the computational approach underlying Figures 4 and 5 and confirms again that this motion is a Berry pseudorotation.

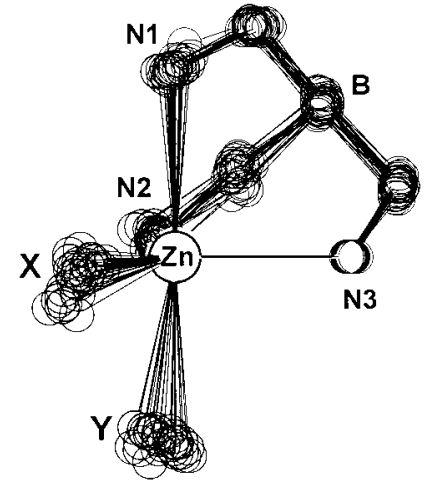

FIGURE 6. Superposition of the structures of the $\operatorname{Tp} * Z n(X)(Y)$ complexes. $\mathrm{Zn}, \mathrm{N1}$, and $\mathrm{N} 3$ in the plane of projection, $\mathrm{Zn}-\mathrm{N} 3$ horizontal, $\mathrm{Tp}^{*}$ ligand reduced to the $\mathrm{BN}_{6}$ frame. The atom labels were chosen such that the sequence of the structures lies within the same half of the $\mathrm{TBP}^{1} \rightarrow \mathrm{SP} \rightarrow \mathrm{TBP}^{2}$ transition. Symmetry requires that a mirrored view of the mirrored structures then populates the other half; i.e., the full Berry pseudorotation is populated by 60 increments. 12,22

To generate a clearer picture of the actual range in space covered by the transition along the individual structures, Figure 7 was constructed using a different viewing angle and plotting only eight $\mathrm{Tp} * \mathrm{Zn}(\mathrm{X})(\mathrm{Y})$ structures. The angular motion covered by $X$ or $Y$ amounts to almost $50^{\circ}$, their bond length change to almost $1 \AA$. Figure 7 is the verification of the $\mathbf{E} \rightarrow \mathbf{F} \rightarrow \mathbf{G}$ transition of Figure 3 , with $\mathrm{X}$ and $\mathrm{Y}$ being equivalents of $\mathrm{O}^{1}$ and $\mathrm{O}^{2}$. The structure correlation method has thus yielded a reaction trajectory which has the combined advantage of being easily imaginable and in accord with theoretical treatments. ${ }^{11}$

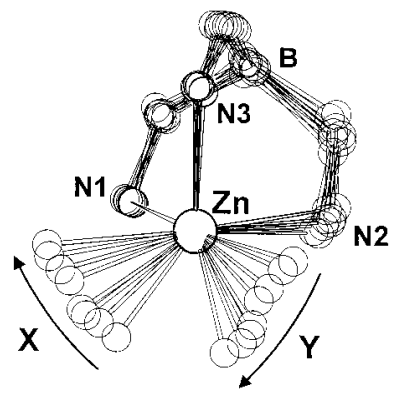

FIGURE 7. Trajectory for the motion of $X$ and $Y$ around zinc during the $\mathbf{E} \rightarrow \mathbf{F} \rightarrow \mathbf{G}$ transition (see Figure 3 ) constructed from eight selected $\operatorname{Tp} * \operatorname{Zn}(X)(Y)$ orientations. 
The approach outlined here can only describe atomic motions in the ligand sphere of zinc. It fits, however, naturally with the approach of the substrate to and the elimination of the product from the catalytic center (i.e., along the axes of trigonal bipyramids, cf. Figure 3). Its mechanistic implications are compatible with the mechanisms known for the interconversions of the substrates, i.e., pseudorotation at phosphorus during nucleophilic substitutions at phosphates and facial attack at $\mathrm{sp}^{2}$ configured carbon during nucleophilic substitutions at acyl compounds. Considering that the coordinative flexibility of a protein providing a $L_{3} Z n$ environment should not be seriously different from that of a Tp* ligand, the mechanistic conclusions concerning the immediate vicinity of the zinc ion should likewise be applicable to enzymatic catalysis.

\section{Conclusions}

This Account describes the views of a preparative and structurally oriented inorganic chemist dealing with metalmediated enzymatic or catalytic reactions: still photos of moving targets which cannot describe the complex motion but are precise in their detail. Three topics pertinent to the function of zinc enzymes were touched. With relation to the title of this Account the Tp*Zn-hydroxide complexes and their chemistry represent the transitions. The structure correlations of the Tp*Zn(X)(Y) complexes represent the transition states, and the $\mathrm{Tp} * \mathrm{Zn}$-inhibitor complexes represent the transition state analogues. The pyrazolylborate zinc complexes compensate for their lack of catalytic properties by a wealth of reactions, stable products, and informative structures. Their recent application in the alkylation of thiols demonstrates that their potential for bioinorganic model systems is not exhausted yet.

This work was supported over the years by generous grants of the DeutscheForschungsgemeinschaft. It was performed by a team of dedicated co-workers whose names are given in the references and who demonstrated their willingness to excel by acquiring the skills for all techniques and methodologies themselves. Egbert Keller, a former co-worker and author of the SCHAKAL program, made valuable contributions.

\section{References}

(1) The numerous textbooks on bioinorganic chemistry lead the way to the secondary literature and the key references on zinc in biology.

(2) (a) Alsfasser, R.; Ruf, M.; Trofimenko, S.; Vahrenkamp, H. A $\mathrm{L}^{3} \mathrm{Zn}-\mathrm{OH}$ complex as a functional model of the enzyme carbonic anhydrase. Chem. Ber. 1993, 126, 703-710. (b) Ruf, M.; Weis, K.; Vahrenkamp, H. A new pyrazolylborate zinc hydroxide complex capable of cleaving esters, amides and phosphates. J. Chem. Soc., Chem. Commun. 1994, 135-136. (c) Ruf, M.; Weis, K.; Vahrenkamp, $\mathrm{H}$. $\mathrm{Zn}-\mathrm{O}_{2} \mathrm{H}_{3}-\mathrm{Zn}$, a coordination mode of the hydrolytic zinc-aqua function and a possible structural motif for oligozinc enzymes. J. Am. Chem. Soc. 1996, 118, 9288-9294. (d) Weis, K.; Vahrenkamp, H. Simple zinc complexes of pyridyl-substituted tris(pyrazolyl)borate ligands. Inorg. Chem. 1997, 36,
5592-5596. (e) Vahrenkamp, H. Coordination chemistry of zinc related to an understanding of its biological functions. In Bioinorganic ChemistryTransition Metals in Biology and their Coordination Chemistry; Trautwein, A. X., Ed.; Wiley-VCH: Weinheim, 1997; pp 540-551.

(3) Cf. Sola, M.; Lledos, A.; Duran, M.; Bertran, J. Anion binding and pentacoordination in zinc(II) complexes. Inorg. Chem. 1991, 30, 2523-2527 and references therein.

(4) (a) Alsfasser, R.; Trofimenko, S.; Looney, A.; Parkin, G.; Vahrenkamp, H. A mononuclear zinc hydroxide complex stabilized by a highly substituted tris(pyrazolyl)hydroborato ligand: analogies with the enzyme carbonic anhydrase. Inorg. Chem. 1991, 30, 4098-4100. (b) Ruf, M.; Vahrenkamp, H. Small molecule chemistry of the pyrazolylborate zinc unit TpCum,MeZn-OH. Inorg. Chem. 1996, 35, 65716578. (c) Ruf, M.; Burth, R.; Weis, K.; Vahrenkamp, $\mathrm{H}$. Coordination of cysteine and histidine derivatives to the pyrazolylborate-zinc unit. Chem. Ber. 1996, 129, 1251-1257.

(5) Gockel, P.; Blindauer, C.; Vahrenkamp, H. Unpublished results. The potentiometric measurements of the water-insoluble $\mathrm{Tp}^{*}$ compounds were performed in water/methanol/dichloromethane using suitable electrodes and referencing procedures.

(6) (a) Ruf, M.; Vahrenkamp, H. Hydrolysis of esters and amides by the metallonucleophile TpCum,MeZn-OH. Chem. Ber. 1996, 129, 1025-1028. (b) Weis, K.; Rombach, M.; Ruf, M.; Vahrenkamp, H. (Pyrazolylborate)zinc organophosphate complexes resulting from hydrolytic cleavage of phosphate esters. Eur. J. Inorg. Chem. 1998, 263-270. (c) Weis, K.; Vahrenkamp, H. Hydrolytic cleavage of diphosphates, sulfonatophosphates, and disulfonates by (pyrazolylborate)zinc hydroxide complexes. Eur. J. Inorg. Chem. 1998, 271-274. (d) Weis, K.; Rombach, M.; Vahrenkamp, H. Attachment of sugar phosphates and nucleotide derivatives to pyrazolylborate-zinc units. Inorg. Chem. 1998, 37, 2470-2475.

(7) (a) Ruf, M.; Schell, F. A.; Walz, R.; Vahrenkamp, H. Chemical interconversions in the system $\mathrm{Tp} * \mathrm{Zn} /$ $\mathrm{CO}_{2}$ /alcohol. Chem. Ber. 1997, 130, 101-104. (b) Walz, R.; Weis, K.; Vahrenkamp, H. Zinc pyrazolylborate complexes with phenoxide and alkoxide ligands. Chem. Ber. 1997, 130, 975-980.

(8) (a) Alsfasser, R.; Powell, A. K.; Trofimenko, S.; Vahrenkamp, $\mathrm{H}$. Monofunctional tetrahedral zinc complexes $\mathrm{L}^{3} \mathrm{Zn}-\mathrm{X}\left(\mathrm{L}^{3}=\right.$ tris(pyrazolyl) borate). Chem. Ber. 1993, 126, 685-694. (b) Burth, R.; Vahrenkamp, $\mathrm{H}$. Monomeric tripod-zinc-thiolate complexes. Z. Anorg. Allg. Chem. 1998, 624, 381-385.

(9) (a) Gonzales, J. C.; Peariso, K.; Penner-Hahn, J. E.; Matthews, R. G. Cobalamine-independent methionine synthase from E. coli: a zinc metalloenzyme. Biochemistry 1996, 35, 12228-12234. (b) Sauer, K.; Thauer, R. Methanol: coenzyme M methyltransferase from methanosarcina barkeri. Eur. J. Biochem. 1997, 249, 280-285. (c) Myers, L. C.; Terranova, M. P.; Ferentz, A. E.; Wagner, G.; Verdine, G. L. Repair of methylphosphotriesters through a metalloactivated cysteine nucleophile. Science 1993, 261, 1164-1167.

(10) Brand, U.; Rombach, M.; Vahrenkamp, H. Methylation of zinc bound thiolates; a model for cobalamine independent methionine synthase. J. Chem. Soc., Chem. Commun. 1998, 2717-2718.

(11) For a compilation of references see ref 12. 
(12) Rombach, M.; Maurer, C.; Weis, K.; Keller, E.; Vahrenkamp, $\mathrm{H}$. Evidence for a trajectory of hydroIytic reactions brought about by $\mathrm{L}_{3} \mathrm{Zn}-\mathrm{OH}$ species. Chem. Eur. J. 1999, 5, 1013-1027.

(13) Wolfenden, R. Analog approaches to the structure of the transition state in enzyme reactions. Acc. Chem. Res. 1972, 5, 10-18.

(14) (a) cf. Nishino, N.; Powers, J. C. Design of potent reversible inhibitors for thermolysin. Biochemistry 1979, 18, 4340-4347. (b) Collins, K. D. An activated intermediate analogue. J. Biol. Chem. 1974, 249, 136-142.

(15) Schulz, G. E.; et al. Unpublished work, cited by Fessner, W. D.; Schneider, A.; Held, H.; Sinerius, G.; Walter, C.; Hixon, M.; Schloss, J. V. On the mechanism of metal-dependent class II aldolases. Angew. Chem., Int. Ed. Engl. 1996, 35, 2219-2221.

(16) Beckett, R. P.; Davidson, A. H.; Drummond, A. H.; Huxley, P.; Whittaker, M. Recent advances in matrix metalloprotease inhibitor research. Drug Discovery Today 1996, 1, 16-26.

(17) (a) Stams, T.; Spurlino, J. C.; Smith, D. L.; Wahl, R. C.; Ho, T. F.; Qoronfleh, M. W.; Banks, T. M.; Rubin, B. Structure of human neutrophil collagenase re veals large $\mathrm{Sl}^{\prime}$ specificity pocket. Nat. Struct. Biol. 1994, 1, 119-126 and references cited therein. (b) Grams, F.; Reinemer, P.; Powers, J. C.; Kleine, T.; Pieper, M.; Tschesche, H.; Huber, R.; Bode, W. X-ray structures of human neutrophil collagenase complexed with peptide hydroxamate and peptide thiol inhibitors. Eur. J. Biochem. 1995, 228, 830-841 and references cited therein.

(18) Ruf, M.; Weis, K.; Brasack, I.; Vahrenkamp, H. Modelling transition state analogues and enzymeinhibitor complexes of zinc-containing class II aldolases and metalloproteases. Inorg. Chim. Acta 1996, 250, 271-281.

(19) (a) Sträter, N.; Lipscomb, W. N.; Klabunde, T.; Krebs, B. Enzymatic acyl and phosphoryl transfer reactions effected by two metal ions. Angew. Chem., Int. Ed. Engl. 1996, 35, 2024-2055. (b) Vallee, B. L.; Auld, D. S. New perspective on zinc biochemistry: cocatalytic sites in multi-zinc enzymes. Biochemistry 1993, 32, 6493-6500.

(20) (a) Bürgi, H. B.; Dunitz, J. D. From crystal statics to chemical dynamics. Acc. Chem. Res. 1973, 16, 153161. (b) Structure Correlation; Bürgi, H.-B., Dunitz, J. D., Eds.; VCH Publishers: Weinheim, 1994.

(21) Holmes, R. R. Structure of cyclic pentacoordinated molecules of main group elements. Acc. Chem. Res. 1979, 12, 257-265.

(22) The weakly associated dimer $T p^{P i c, M e} \mathrm{Zn}-\mathrm{I}$ having as $\mathrm{Zn}-\mathrm{Y}$ an extremely long (3.02 $\AA$ ) $\mathrm{Zn}-\mathrm{N}$ contact was not plotted in this figure in order to avoid confusion.

AR9703185 